\title{
Lack of association of colonic epithelium telomere length and oxidative DNA damage in Type 2 diabetes under good metabolic control
}

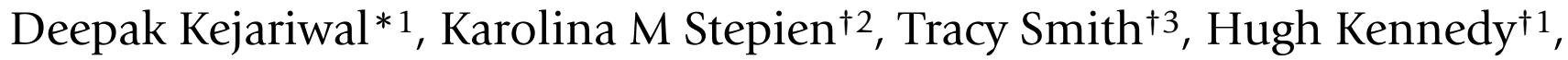 \\ David A Hughes ${ }^{\dagger 3}$ and Mike J Sampson ${ }^{\dagger 2}$
}

Address: ${ }^{1}$ Department of Gastroenterology, Norfolk and Norwich University Hospital Colney Lane, Norwich NR4 7UY, UK, ${ }^{2}$ Elsie Bertram Diabetes Centre, Norfolk and Norwich University Hospital, Norwich NR4 7UA, UK and ${ }^{3}$ Institute of Food Research, Norwich Research Park, Colney, Norwich NR4 7UA, UK

Email: Deepak Kejariwal* - dkejariwal@aol.com; Karolina M Stepien - kstepien@doctors.org.uk; Tracy Smith - tracey.smith@bbsrc.ac.uk; Hugh Kennedy - hugh.kennedy@nnuh.nhs.uk; David A Hughes - davida.hughes@bbsrc.ac.uk; Mike J Sampson - mike.sampson@nnuh.nhs.uk

* Corresponding author †Equal contributors

Published: 10 October 2008

BMC Endocrine Disorders 2008, 8:12 doi:10.1186/1472-6823-8-12
Received: II May 2008

Accepted: 10 October 2008

This article is available from: http://www.biomedcentral.com/I472-6823/8/12

(c) 2008 Kejariwal et al; licensee BioMed Central Ltd.

This is an Open Access article distributed under the terms of the Creative Commons Attribution License (http://creativecommons.org/licenses/by/2.0), which permits unrestricted use, distribution, and reproduction in any medium, provided the original work is properly cited.

\begin{abstract}
Background: Telomeres are DNA repeat sequences necessary for DNA replication which shorten at cell division at a rate directly related to levels of oxidative stress. Critical telomere shortening predisposes to cell senescence and to epithelial malignancies. Type 2 diabetes is characterised by increased oxidative DNA damage, telomere attrition, and an increased risk of colonic malignancy. We hypothesised that the colonic mucosa in Type 2 diabetes would be characterised by increased DNA damage and telomere shortening.

Methods: We examined telomere length (by flow fluorescent in situ hybridization) and oxidative DNA damage (flow cytometry of 8 - oxoguanosine) in the colonic mucosal cells of subjects with type 2 diabetes ( $n=10$; mean age 62.2 years, mean HbAlc 6.9\%) and 22 matched control subjects. No colonic pathology was apparent in these subjects at routine gastrointestinal investigations.

Results: Mean colonic epithelial telomere length in the diabetes group was not significantly different from controls (I0.6 [3.6] vs. 12.1 [3.4] Molecular Equivalent of Soluble Fluorochrome Units [MESF]; $P=0.5$ ). Levels of oxidative DNA damage were similar in both T2DM and control groups (2.6 [0.6] vs. 2.5 [0.6] Mean Fluorescent Intensity [MFI]; $P=0.7)$. There was no significant relationship between oxidative DNA damage and telomere length in either group (both $p>0.1$ ).

Conclusion: Colonic epithelium in Type 2 diabetes does not differ significantly from control colonic epithelium in oxidative DNA damage or telomere length. There is no evidence in this study for increased oxidative DNA damage or significant telomere attrition in colonic mucosa as a carcinogenic mechanism.
\end{abstract}

\section{Background}

Type 2 diabetes mellitus (T2DM) is associated with a 40$60 \%$ increased risk of colorectal carcinoma $[1,2]$. The mechanisms underlying this association remain unclear. We have suggested recently [3] that one unexplored mechanism for this association is increased oxidative DNA 
damage and telomere attrition. Telomere-length abnormalities in epithelial cells occur very early in the development of many epithelial-derived tumours [4], including the transition from adenoma to carcinoma in colorectal epithelial cells $[4,5]$.

Telomeres are tandem repeats of the hexanucleotide DNA sequence, TTAGGG at the end of eukaryotic chromosomes. Telomeres in somatic human cells shorten with every cell division and once shortened to a critical length become dysfunctional. Dysfunctional telomeres activate p53 to initiate cellular senescence or apoptosis to suppress tumorigenesis [6]. However, in the absence of p53, cells can escape the senescence checkpoint and continue to shorten their telomeres, resulting in entry into a phase of chromosomal instability characterized by chromosomal fusions and non-reciprocal translocations (NRTs) [7,8] commonly found in human epithelial carcinomas [9]). Loss of p53 function characterizes most human carcinomas and p53 mutations occur in $40-60 \%$ of colorectal adenocarcinomas $[10,11]$.

Rates of telomere shortening, and therefore telomere length, are highly dependent on oxidatively-induced strand breaks in telomeric DNA and on cellular oxidant balance [12-15]. Telomeric DNA is particularly prone to oxidative damage at the GGG sequence, and it is probable that oxidatively induced single-and double strand DNA breaks in people with type 2 diabetes $[16,17]$ would translate into accelerated telomere shortening and telomere dysfunction. We and others have shown that monocyte DNA from subjects with T2DM is characterised by increased susceptibility to oxidative damage and telomere shortening [16-18]. However we do not know if similar changes occur in tissues at risk of epithelial cancer development in T2DM. We hypothesized that patients with T2DM would demonstrate shorter telomeres in colonic epithelium compared with control subjects and this would be directly related to markers of oxidative DNA damage.

\section{Methods}

All subjects gave written informed consent to participate in this study, which was approved by the local Research Ethics Committee. The patients were recruited from subjects attending our Gastroenterology Department for non urgent diagnostic endoscopy for clinical reasons. Up to six additional biopsies from the sigmoid colon were obtained for the study.

\section{Subjects and controls}

Subjects were included if they were Caucasian non smokers in an intentionally narrow age range of $50-70$ years to limit confounding by age and other variables. Mean age in control group was 61.5 years and 62.2 among patients with T2DM. Male sex dominated with 15 in control group and 8 among patients with diabetes (Table 1). We excluded patients with abnormal lower GI endoscopy or patients with a previous history of inflammatory bowel disease, colon cancer or polyps. Subjects self medicating with any dietary vitamin or fish oil supplements were excluded. The T2DM patients were treated with metformin alone $(\mathrm{n}=3)$, sulfonylureas alone $(\mathrm{n}=1)$, metformin and sulfonylureas in combination $(n=3)$ or subcutaneous insulin $(n=2)$. Three of the 10 T2DM patients had background diabetic retinopathy $(\mathrm{n}=2)$, nephropathy with macroproteinuria $(n=1)$ or peripheral neuropathy $(\mathrm{n}=1)$. All subjects had a complete large bowel examination either by a colonoscopy or a flexible sigmoidoscopy and barium enema. The commonest indications for the evaluation of the large bowel were bleeding per rectum ( $n=12$ in control and $n=5$ in type 2 diabetics) and change in bowel habit ( $\mathrm{n}=7$ in control, $\mathrm{n}=2$ in diabetic subjects). Other indications for the test were family history of colorectal cancer ( $\mathrm{n}=3$ in controls), anaemia ( $\mathrm{n}$

Table I: Clinical features of type $\mathbf{2}$ diabetes and control groups

\begin{tabular}{|c|c|c|c|}
\hline & Control subjects & Type 2 diabetes & $\mathrm{P}$ \\
\hline$N$ & 22 & 10 & \\
\hline Age (years) & $61.5 \pm 5.5$ & $62.2 \pm 7.5$ & $P=0.76$ \\
\hline M:F & $15: 7$ & $8: 2$ & \\
\hline Diabetes duration (years) & - & $6.5(7.75)$ & \\
\hline BMI $\left(\mathrm{kg} / \mathrm{m}^{2}\right)$ & $26.6 \pm 4.5$ & $28.1 \pm 6.9$ & $P=0.46$ \\
\hline $\mathrm{HbAlc}(\%)$ & - & $6.9 \pm 0.7$ & \\
\hline Systolic blood pressure $(\mathrm{mmHg})$ & $145.8 \pm 21.8$ & $144.7 \pm 16.9$ & $P=0.88$ \\
\hline Diastolic blood pressure $(\mathrm{mmHg})$ & $89.6 \pm 11.3$ & $80.1 \pm 9.3$ & $P=0.03$ \\
\hline Statin use (n) & 5 & 9 & $P=0.0005$ \\
\hline ACE inhibitors $(n)$ & 2 & 4 & $P=0.05$ \\
\hline Aspirin (n) & 3 & 6 & $P=0.01$ \\
\hline
\end{tabular}

Data are means \pm SD or median (interquartile range).

$\mathrm{BMI}$ - body Mass Index

HbAlc - glycosylated hemoglobin 
$=2$ in diabetics $)$ and colorectal cancer screening $(\mathrm{n}=1$ in diabetics).

\section{Isolation of Cells}

Six biopsies obtained from the sigmoid colon were immediately placed in Hanks Balanced Salt Solution (HBSS) (Sigma, UK) and transported on ice to the laboratory. Upon arrival ( $<60 \mathrm{~min}$ ) biopsies were minced using a surgical scalpel and incubated with $3 \mathrm{mg}$ collagenase (Roche Applied Science, UK) and $6 \mathrm{mg}$ proteinase K (Sigma, UK) in $3 \mathrm{ml} \mathrm{HBSS}$ at $37^{\circ} \mathrm{C}$ for $1-1.5 \mathrm{~h}$. Samples were resuspended every $15 \mathrm{~min}$ and once digested made up to $15 \mathrm{ml}$ with HBSS. The suspension was then passed through a 70 um cell strainer (BD Falcon, UK) and centrifuged for 5 min $1400 \mathrm{rpm}$. The resulting pellet was resuspended in 1 $\mathrm{ml}$ cell freezing medium (Sigma UK) and divided equally between 2 cryovials. Cells were stored in liquid nitrogen prior to analysis.

\section{Telomere length}

Telomere length of isolated mucosal cells was measured using a Dako Telomere PNA (Peptide Nucleic Acid) Kit/ FITC (fluorescein isothiocyanate) for flow cytometry (Dako Cytometry, Ely, UK), as we have previously described [18], in combination with an anti-cytokeratin (CAM 5.2) (BD Biosciences, San Jose, CA) epithelial marker.

Thawed, cryopreserved cells were aliquoted into 2 tubes and resuspended in either 100 ul of hybridisation buffer containing the FITC/PNA probe or $100 \mathrm{ul}$ of hybridisation buffer without probe. Both aliquots were then heated in a water bath at $82^{\circ} \mathrm{C}$ for $10 \mathrm{~min}$, before being left in the dark at room temperature overnight to hybridise. After washing twice with wash buffer, $10 \mathrm{~min}$ at $40^{\circ} \mathrm{C}, 20 \mathrm{ul}$ of PE (phycoerythrin) - labeled anti - CK (cytokeratin) was added to identify the epithelial population. Cells were then incubated at room temperature in the dark for 30 min before washing with PBS. Finally 125 ul of propidium iodide (PI) was added to each tube and incubated in the dark at $4{ }^{\circ} \mathrm{C}$ for a minimum of $2 \mathrm{~h}$ prior to analysis. The mean telomere fluorescence of $\mathrm{CK}$ positive single cells was recorded by flow cytometry (Cytomics FC500MPL, Beckman Coulter) and calculated as the difference between the mean fluorescence of cells hybridised in the presence of the FITC-PNA probe and those hybridised in buffer. Telomere fluorescence data were then converted into molecular equivalent of soluble fluorochrome units (MESF) using Quantum premixed low level MESF beads (Bang Laboratories, Inc. Fishers, IN) which were run with each experiment.

\section{Oxidative DNA damage}

Oxidative DNA damage in epithelial cells was assessed using a Biotrin OxyDNA test kit (Biotrin, Dublin, Ireland) in combination with the anti-CK epithelial marker. Immediately after cryopreserved cells were thawed and washed in phosphate buffered saline (PBS) they were fixed and permeablised using a Fix and Perm kit (Caltag Labs, Burlingame, CA). Oxidative DNA damage was determined using a FITC-labeled 8-oxoguanine probe as directed by manufacturer, as we have used previously [18]. However $30 \mathrm{~min}$ from the end of incubation with the FITC probe $20 \mathrm{ul}$ of PE - labeled anti - cytokeratin (CAM 5.2) was added to label the epithelial population. Cells were then washed twice in PBSAA (PBS + 0.1\% BSA $+0.02 \%$ azide) and the mean fluorescent intensity (MFI) of CK positive cells recorded by flow cytometry (Cytomics FC500MPL, Beckman Coulter).

\section{Data analysis and power calculations}

Data are expressed as mean \pm SD or as median (interquartile range) as appropriate. Differences between groups were analyzed by unpaired t test or Mann-Whitney U tests as appropriate and significance taken as $\mathrm{P}<0.05$. Differences between distributions of variables between groups were analyzed by Fishers exact text. No adequate previous data were available to allow sample size calculations. However, a total sample size of at least 40 between 2 groups would give $80 \%$ power at the $5 \%$ level to detect a one standard deviation difference between group means, which appears to be a biologically relevant difference $[19,20]$.

\section{Results \\ Clinical features}

Clinical details of the two groups are shown (Table 1). The T2DM subjects were in good glycemic control (mean HbA1c $6.9 \%$ ) after a median diabetes duration of 6.5 years.

\section{Telomere length by flow-fluorescent in situ hybridization and oxidative DNA damage}

In the T2DM group, colonic epithelial cell $(\mathrm{CK}+)$ MESF was not significantly different than in control subjects (10.6 [3.6] vs. 12.1 [3.4]; $p=0.5$ ). Similarly the MESF of total mucosal cell populations in the diabetic subjects were non significantly lower than in control subjects $(8.2$ [2.8] vs. 9.2 [2.8]; $\mathrm{p}=0.6$ ). Oxidative DNA damage (8oxoguanine levels) in the colonic epithelial cells (CK+) was similar in both the diabetic and control subjects (2.6 [0.6] vs. 2.5 [0.6] MFI) (Table 2).

\section{Determinants of telomere length}

There was no significant relationship between epithelial cell oxidative DNA damage and telomere length in either T2DM $(\mathrm{r}=+0.24, \mathrm{p}=0.5)$ or control groups $(\mathrm{r}=0.32, \mathrm{p}=$ 0.1 ). The relationship between age or BMI (Body Mass Index) and telomere length was not significant in either group. 
Table 2: Telomere length and oxidative DNA damage in subjects with or without type 2 diabetes

\begin{tabular}{cccc}
\hline & Control subjects & Type 2 diabetes & $P$ \\
\hline$n$ & 22 & 10 & \\
Telomere length & & $10.6 \pm 3.6$ & $P=0.27$ \\
CK+ cells & $12.1 \pm 3.4$ & $8.2 \pm 2.8$ & $P=0.38$ \\
All cells & $9.2 \pm 2.8$ & $2.6 \pm 0.6$ & $P=0.76$ \\
Oxidative DNA damage & $2.5 \pm 0.6$ & $2.2 \pm 0.6$ & $P=0.83$ \\
CK+ cells & $2.2 \pm 0.6$ & & \\
All cells & & & \\
\end{tabular}

Data are means \pm SD. Data as MESF for telomere length and MFI for 8-oxoguanine as a marker of oxidative DNA damage.

\section{Discussion}

The main findings in this study are that colonic epithelial cell telomere length and oxidative DNA damage were not significantly different in T2DM compared to controls, and that there was no significant relationship between oxidative DNA damage and telomere length in either group.

Colorectal cancer is characterized by sequential morphological changes of the colonic mucosa spanning the adenoma-carcinoma transition coupled with increasing genetic alterations. Telomere shortening, characterizes the adenoma-carcinoma transition, is apparent in the earliest detectable epithelial carcinoma stage $[4,5]$, and in pre malignant states for colonic carcinomas $[19,20]$.

Oxidative damage to DNA is widely thought to be a significant contributor to the age related development of major cancer $[2,19,21]$. We have recently shown an inverse association of telomere shortening and oxidative DNA damage [18] in circulating mononuclear cells in T2DM that could be due to increased oxidative DNA damage to monocyte precursors during cell division [18]. A number of other studies have also shown that systemic oxidative stress assessed by various biomarkers $[23,24]$ is associated with shorter telomere lengths in peripheral blood leukocytes (PBL). These studies have used PBL telomere length as a systemic measure supported by the observation that telomere length is to a large extent conserved among different tissues. Telomere length could offer a link between oxidative stress and the predisposition to epithelial cancers in T2DM [3].

This is the first study measuring the telomere length and oxidative DNA damage in the colonic epithelium in type 2 diabetics, but we found no significant differences. The strength of this study is that the T2DM group was selected to limit confounding by variables that influence the risk of colorectal cancer such as race, age, smoking, polyps and inflammatory bowel disease. Moreover, the whole of the large bowel was imaged. This ensured that the measurements were truly from normal colonic mucosa. The main limitation of the study was small sample size in the diabetic patients. However, post hoc analysis suggests that this small study had $80 \%$ power to detect a difference of 2.66 MESF (0.7 SD) in the mean telomere length difference between the controls and T2DM at the 5\% level.

Another possible confounding is the significantly higher use of aspirin, ACE and statins in the T2DM group. Available data suggest a neutral or protective effect of statins on telomere length or damage in vitro $[25,26]$. Aspirin has anti-inflammatory properties by inhibiting cyclooxygenase enzymes and substantially lower the risk of colon cancer [27]. ACE inhibitors have free radical scavenging properties and reduce oxidative stress [28,29]. It should also be stressed that the T2DM groups were in good glycemic control and glycemic control is an important risk factor for colorectal cancer [30]. The median duration of diabetes was 6.5 years. This may be another confounding factor as perhaps a longer duration of diabetes may be needed to demonstrate a toxic effect on the colonic epithelium.

\section{Conclusion}

The present study therefore, found no data to support a substantially increased oxidative DNA damage or telomere attrition in the colonic mucosa in T2DM. This is an important area for investigation in view of growing interest in increased epithelial malignancy rates in T2DM.

\section{Abbreviations}

T2DM: Type 2 diabetes mellitus; NRTS: non-reciprocal translocations; HBSS: Hanks Balanced Salt Solution; PNA: Peptide Nucleic Acid; MESF: molecular equivalent of soluble fluorochrome units; PBS: phosphate buffered saline; PE: phycoerythrin; FITC: fluorescein isothiocyanate; PBL: peripheral blood leucocytes.

\section{Competing interests}

The authors declare that they have no competing interests.

\section{Authors' contributions}

DK and KMS collected the data. DK analysed the data and drafted the manuscript. TS and DAH carried out the telomere length and oxidative DNA assays. DAH and HK helped in designing the study and drafting the manu- 
script. MJS conceived of the study, and participated in design and coordination and helped to draft the manuscript. All authors read and approved the final manuscript.

\section{Acknowledgements}

This work was funded by the Elsie Bertram Diabetes Centre and the Biotechnology and Biological Sciences Research Council, UK. We thank Dr.

Roy Bongaerts for his expert advice on the flow cytometric techniques. We thank Dr. Sneha John for her managerial help with the study.

\section{References}

I. Will JC, Galuska DA, Vinicor F, Calle EE: Colorectal cancer: another complication of diabetes mellitus? Am J Epidemiol 1998, 147:816-825.

2. Hu FB, Manson JE, Liu S, Hunter D, Colditz GA, Michels KB: Prospective study of adult onset diabetes mellitus (type 2) and risk of colorectal cancer in women. J Natl Cancer Inst 1999, 9I:542-547.

3. Sampson MJ, Hughes DA: Chromosomal telomere attrition as a mechanism for the increased risk of epithelial cancers and senescent phenotypes in type 2 diabetes. Diabetologia 2006, 49(8): 1726-173|.

4. Meeker AK, Hicks JL, lacobuzio-Donahue CA: Telomere length abnormalities occur early in the initiation of epithelial carcinogenesis. Clin Cancer Res 2004, 10:3317-3326.

5. Plentz RR, Wiemann SU, Flemming P: Telomere shortening of epithelial cells characterises the adenoma-carcinoma transition of human colorectal cancer. Gut 2003, 52:1304-1307.

6. Deng $Y$, Chang S: Role of telomeres and telomerase in genomic instability, senescence and cancer. Laboratory Investigation 2007, 87: 107I-1076.

7. Counter CM, Avilion AA, LeFeuvre CE: Telomere shortening associated with chromosome instability is arrested in immortal cells which express telomerase activity. EMBO J 1992, I I: I921-1929.

8. Chang S, Khoo C, Naylor M: Telomere-based crisis: functional differences between telomerase activation and ALT in tumor progression. Genes and Development 2003, 17:88-100.

9. Hanahan D: Benefits of bad telomeres. Nature 2000, 406:573-574.

10. Hollstein M, Sidransky D, Vogelstein B: p53 mutations in human cancers. Science 1991, 253:49-53.

11. Veloso M, Wrba F, Kaserer K: p53 gene status and expression of p53, mdm2, and p2IWafl/Cipl proteins in colorectal cancer. Virchows Arch 2000, 437:24I-247.

12. von Zglinicki T: Role of oxidative stress in telomere length regulation and replicative senescence. Ann N Y Acad Sci 2000, 908:99-110.

13. Oikawa S, Kawanishi S: Site-specific DNA damage at GGG sequence by oxidative stress may accelerate telomere shortening. FEBS Lett I991, 453:365-368.

14. von Zglinicki T, Pilger R, Sitte N: Accumulation of single-strand breaks is the major cause of telomere shortening in human fibroblasts. Free Radic Biol Med 2000, 28:64-74.

15. Serra V, Grune T, Sitte N, Saretzki G, von Zglinicki T: Telomere length as a marker of oxidative stress in primary human fibroblast cultures. Ann NY Acad Sci 2000, 908:327-330.

16. Sampson MJ, Astley S, Richardson T, Willis G, Davies IR, Hughes DA: Increased DNA oxidative susceptibility without increased plasma LDL oxidizability in type II diabetes: effects of alphatocopherol supplementation. Clin Sci (Lond) 200I, I0 I:235-24I.

17. Rehman A, Nourooz-Zadeh J, Moller W, Tritschler H, Pereira P, Halliwell B: Increased oxidative damage to all DNA bases in patients with type II diabetes mellitus. FEBS 1999, 448: $120-122$.

18. Sampson MJ, Winterbone MS, Hughes JC, Dozio N, Hughes DA: Monocyte telomere shortening and oxidative DNA damage in type 2 diabetes. Diabetes Care 2006, 29(2):283-289.

19. O'Sullivan J, Risques RA, Mandelson MT, Chen L, Brentnall TA, Bronner MP, Macmillan MP, Feng Z, Siebert JR, Potter JD, Rabinovitch PS: Telomere length in the colon declines with age: a relation to colorectal cancer? Cancer Epidemiol Biomarkers Prev 2006, I5(3):573-577.

20. Kinouchi $Y$, Hiwatashi N, Chida M, Nagashima F, Takagi S, Maekawa $\mathrm{H}$, Toyota $\mathrm{T}$ : Telomere shortening in the colonic mucosa of patients with ulcerative colitis. J Gastroenterol 1998, 33(3):343-348.

21. Halliwell B, Gutteridge JMC: Free radicals in biology and medicine. 3rd edition. Oxford, United Kingdom: Oxford University Press; 1999.

22. Leinonen J, Lehtimaki T, Toyokuni S, Okada K, Tanaka T, Hiai H, Ochi $\mathrm{H}$, Laippala P, Rantalaiho V, Wirta O, Pasternack A, Alho H: New biomarker evidence of oxidative DNA damage in patients with non-insulin-dependent diabetes mellitus. FEBS Lett 1997 , 417:150-152.

23. Demissie S, Levy D, Benjamin EJ, Cupples LA, Gardner JP, Herbert A: Insulin resistance, oxidative stress, hypertension, and leukocyte telomere length in men from the Framingham Heart Study. Aging Cell 2006, 5:325-330.

24. Adaikalakoteswari A, Balasubramanyam M, Mohan V: Telomere shortening occurs in Asian Indian type 2 diabetic patients. Diabetic Med 2005, 22: I I5I-1I 56.

25. Spyridopoulos I, Haendeler J, Urbrich C, Brummendorf TH, Oh H, Schneider MD, Zeiher AM, Dimmeler S: Statins enhance migratory capacity by upregulation of the telomere repeat binding factor TRF-2 in endothelial progenitor cells. Circulation 2004, I I 0:3 |36-3|42.

26. Brouilette SW, Moore JS, McMahon AD, Thompson JR, Ford I, Shepherd J, Packard C], Samani NJ: West of Scotland Coronary Prevention Study Group. Telomere length, risk of coronary heart disease, a statin treatment in the West of Scotland Primary Prevention Study: a nested case-control study. Lancet 2007, 369(9556): 107-I I4.

27. Markowitz SD: Aspirin and colon cancer - targeting prevention? N Engl J Med 2007, 356(2I):2195-2198.

28. Mira ML, Silva MM, Queiroz MJ, Manso CF: Angiotensin converting enzyme inhibitors as oxygen free radical scavengers. Free Radic Res Commun 1993, 19(3): 173-8I.

29. Scribner AW, Loscalzo J, Napoli C: The effect of angiotensin-converting enzyme inhibition on endothelial function and oxidant stress. Eur J Pharmacol 1997, 482:95-99.

30. Khaw KT, Wareham N, Bingham S, Luben R, Welch A, Day N: Preliminary communication: glycated hemoglobin, diabetes, and incident colorectal cancer in men and women: a prospective analysis from the European prospective investigation into cancer-Norfolk study. Cancer Epidemiol Biomarkers Prev 2004, 13(6):915-919.

\section{Pre-publication history}

The pre-publication history for this paper can be accessed here:

http://www.biomedcentral.com/1472-6823/8/12/prepub

Publish with Bio Med Central and every scientist can read your work free of charge

"BioMed Central will be the most significant development for disseminating the results of biomedical research in our lifetime."

Sir Paul Nurse, Cancer Research UK

Your research papers will be:

- available free of charge to the entire biomedical community

- peer reviewed and published immediately upon acceptance

- cited in PubMed and archived on PubMed Central

- yours - you keep the copyright 